\title{
ORIGINAL ARTICLE \\ Paternity analysis reveals wide pollen dispersal and high multiple paternity in a small isolated population of the bird-pollinated Eucalyptus caesia (Myrtaceae)
}

\begin{abstract}
N Bezemer ${ }^{1,2,3}$, SL Krauss ${ }^{1,2}$, RD Phillips ${ }^{2,4}$, DG Roberts ${ }^{2,3}$ and SD Hopper ${ }^{1,3}$
Optimal foraging behaviour by nectavores is expected to result in a leptokurtic pollen dispersal distribution and predominantly near-neighbour mating. However, complex social interactions among nectarivorous birds may result in different mating patterns to those typically observed in insect-pollinated plants. Mating system, realised pollen dispersal and spatial genetic structure were examined in the bird-pollinated Eucalyptus caesia, a species characterised by small, geographically disjunct populations. Nine microsatellite markers were used to genotype an entire adult stand and 181 seeds from 28 capsules collected from 6 trees. Mating system analysis using MLTR revealed moderate to high outcrossing $\left(t_{m}=0.479-0.806\right)$ and low estimates of correlated paternity $\left(r_{p}=0.136 \pm\right.$ s.e. 0.048$)$. Paternity analysis revealed high outcrossing rates (mean $\left.=0.72\right)$ and high multiple paternity, with 64 different sires identified for 181 seeds. There was a significant negative relationship between the frequency of outcross mating and distance between mating pairs. Realised mating events were more frequent than expected with random mating for plants $<40 \mathrm{~m}$ apart. The overall distribution of pollen dispersal distances was platykurtic. Despite extensive pollen dispersal within the stand, three genetic clusters were detected by STRUCTURE analysis. These genetic clusters were strongly differentiated yet geographically interspersed, hypothesised to be a consequence of rare recruitment events coupled with extreme longevity. We suggest that extensive polyandry and pollen dispersal is a consequence of pollination by highly mobile honeyeaters and may buffer $E$. caesia against the loss of genetic diversity predicted for small and genetically isolated populations.
\end{abstract}

Heredity (2016) 117, 460-471; doi:10.1038/hdy.2016.61; published online 17 August 2016

\section{INTRODUCTION}

Although the steepness and length of pollen dispersal curves varies among species, they are typically leptokurtic, with the frequency of mating events decreasing with distance between mating pairs (Levin and Kerster, 1974; Morris et al., 1995). Leptokurtic pollen dispersal by animals may be attributed to optimal foraging behaviour, where animals forage to maximise energy reward relative to energy loss (Pyke, 1984). Foraging animals typically move between flowers on a single plant, and then on to a near neighbour (Harder and Barrett, 1996) that may be a genetic relative if seed dispersal is limited. Optimal foraging behaviour by nectar- or pollen-feeding animals is therefore expected to result in short-distance pollen dispersal and frequent self-pollination and biparental inbreeding.

Social interactions among nectar-feeding birds that otherwise display optimal foraging patterns on flowers, such as territoriality and the defence of nectar resources, may lead to deviations from optimal foraging behaviour (Mac Nally et al., 2005; Phillips et al., 2014), with potentially novel genetic consequences for plant mating patterns. The defence of nectar resources has been widely documented in honeyeaters, a key pollinator group in temperate Australia (Ford et al., 1979; Hopper and Moran, 1981; Ford and Paton, 1982). For example, large species such as Red Wattlebirds (Anthochaera carunculata), Western Wattlebirds (A. lunulata) and Spiny-cheeked Honeyeaters (Acanthagenys rufogularis) frequently chase away the smaller Brown Honeyeaters (Lichmera indistincta) and Western Spinebills (Acanthorhynchus superciliosus) while foraging on Eucalyptus stoatei (Hopper and Moran, 1981) and a similar pattern of behavioural dominance has been observed between groups of New Holland Honeyeaters and individual Western Spinebills during foraging bouts on Anigozanthos flavidus (Phillips et al., 2014). Therefore, pollination systems involving nectar-feeding honeyeaters that frequently move between widely spaced plants as a consequence of aggressive interactions may facilitate wide outcrossing and high multiple paternity, potentially enhancing genetic diversity and evolutionary potential (Hopper, 1981). In the absence of aggressive interactions, greater pollen carryover by birds compared with insects could still influence multiple paternity and sire diversity in bird-pollinated plants (Mitchell et al., 2013). High pollen carryover by birds could explain long-distance pollen dispersal between populations of tree species with generalist pollination systems (Byrne et al., 2008; Mimura et al., 2009).

Although field observations of honeyeater behaviour in numerous plant species support predictions of more widespread pollen dispersal

${ }^{1}$ School of Plant Biology, The University of Western Australia, Crawley, Western Australia, Australia; ${ }^{2}$ Botanic Gardens and Parks Authority, Fraser Avenue, Kings Park and Botanic Garden, West Perth, Western Australia, Australia; ${ }^{3}$ Centre of Excellence in Natural Resource Management, The University of Western Australia, Albany, Western Australia, Australia and ${ }^{4}$ Evolution, Ecology and Genetics, Research School of Biology, The Australian National University, Canberra, Australian Capital Territory, Australia

Correspondence: N Bezemer, Centre of Excellence in Natural Resource Management, The University of Western Australia, 35 Stirling Terrace, Albany, Western Australia 6332, Australia.

E-mail: nicole.bezemer@research.uwa.edu.au

Received 9 February 2016; revised 31 May 2016; accepted 24 June 2016; published online 17 August 2016 
than would be expected under insect pollination (Hopper and Moran, 1981; Ramsey, 1988; Phillips et al., 2010), few studies have addressed the realised genetic consequences of this behaviour for the plants that they pollinate. Paternity studies in southwest Australian banksias suggest that departures from optimal foraging by honeyeaters can lead to wide outcrossing and very high multiple paternity (Krauss et al., 2009; Ritchie and Krauss, 2012), and that population size, shape and isolation affect honeyeater visitation patterns and plant paternity (Llorens et al., 2012). In A. flavidus, studies of seed germinability suggest that the foraging behaviour of Western Spinebills may facilitate high offspring fitness, potentially aiding the persistence of small populations (Phillips et al., 2014). However, the drivers and consequences of contrasting pollen dispersal patterns in different species pollinated by nectar-feeding birds remain poorly understood.

Population genetic theory predicts that small, isolated plant populations can experience a loss of genetic diversity through genetic drift and/or inbreeding from self-pollination or mating among close relatives (Ellstrand and Elam, 1993). In extreme cases, this can lead to inbreeding depression or even population sterility (DeMauro, 1993; Husband and Schemske, 1996). For example, self-pollination can result in depressed seed set and plant growth compared with controlled outcrossed pollinations in some eucalypts (Hardner and Potts, 1995). However, multiple mating and pre- or post-dispersal selection against inbred individuals has fitness benefits that may buffer the loss of genetic diversity in small populations (Harder and Potts, 1997; Pannell and Labouche, 2013; Roberts et al., 2014). Rare, localised endemics with limited dispersability may have evolved pollination strategies in response to prolonged isolation to maintain or enhance polyandry and genetic diversity (the James Effect hypothesis; sensu Hopper, 2009). For example, field observations of birdpollinated plants in southwest Australia suggest pollination by highly mobile nectar-feeding birds as one potential mechanism facilitating wide outcrossing and thus conserving heterozygosity (Hopper, 1981, 2009). More research is needed to evaluate whether bird pollination has novel genetic consequences for the numerous honeyeater-pollinated plants in Australia, and to explore its potential relevance to other bird-pollinated plants.

The South West Australian Floristic Region (SWAFR, sensu Hopper and Gioia, 2004) has the highest known global incidence of vertebrate pollination (Phillips et al., 2010). Approximately $15 \%$ of ca. 7400 plant species are pollinated by birds or small mammals, including a remarkable 40\% of rare species (Keighery, 1980; Hopper et al., 1990). Despite the pervasiveness of vertebrate pollination in the SWAFR, the ecological and evolutionary significance of vertebrate pollination remains unclear. Eucalyptus caesia Benth. (Myrtaceae) is a rare species that is endemic to 25 granite outcrops in the Central Wheatbelt of Western Australia (Figure 1). As a bird-pollinated species with accentuated persistence in small, insular populations (Moran and Hopper, 1983; Byrne and Hopper, 2008), E. caesia is a model system to assess the generality of near-random mating patterns identified in some bird-pollinated banksias, and to test for beneficial genetic consequences of bird pollination, as predicted by the James Effect hypothesis (Krauss et al., 2009; Ritchie and Krauss, 2012). Furthermore, E. caesia presents an opportunity to study mating system and pollination in an intact, natural setting, whereas previous studies of pollen movement in bird-pollinated species in Australia have largely focussed on populations affected by recent habitat fragmentation (Byrne et al., 2007; Breed et al., 2012; Llorens et al., 2012; Ritchie and Krauss, 2012).

In this study, we explore the genetic consequences of bird pollination using molecular analysis of progeny arrays in E. caesia.
We predict that pollination by honeyeaters will result in wide outcrossing, high multiple paternity and non-leptokurtic pollen dispersal. We then assess the extent to which spatial genetic structure of the adult population is predictable from the observed mating system. Although limited seed dispersal and extensive asexual reproduction via lignotubers suggests a strong likelihood of high spatial genetic structuring within populations, we predict that wide pollen dispersal within the study population will result in weaker spatial genetic structuring than expected if pollination and seed dispersal were both limited.

\section{MATERIALS AND METHODS}

\section{Study species and study site}

E. caesia is a granite outcrop-endemic, monoecious, winter-flowering mallee or small tree with large pink flowers (Figure 2). Whether E. caesia is, like most eucalypts, self-compatible but with a predominantly outcrossing mating system (House, 1997) is unknown. Two subspecies are recognised (Brooker and Hopper, 1982). E. caesia subsp. caesia extends across the species' full geographic range, whereas E. caesia subsp. magna is confined to six stands in the northeast sector of the Central Wheatbelt (Figure 1). At least eight species of honeyeaters (Meliphagidae) act as the primary pollinators of E. caesia, though the flowers are also visited by native and introduced insects such as the introduced honeybee (Apis mellifera) and occasionally small marsupials (Hopper, 1981). It is unknown whether the latter groups effect pollination, although generally high visitation rates by $A$. mellifera suggest a strong possibility for pollination by this species. Seed dispersal in E. caesia has not been studied but is likely by gravity, although secondary dispersal may occur through movement by wind or water, or by parrots feeding on seed capsules (House, 1997). E. caesia reproduces sexually, and asexually via resprouting from lignotubers (Hopper et al., 1982). Surveys in multiple populations conducted over 30 years by SD Hopper indicate that flowering is asynchronous.

The present study focussed on the E. caesia subsp. caesia stand within Boyagin Nature Reserve $\left(32^{\circ} 28^{\prime} 21.0^{\prime \prime S} 116^{\circ} 52^{\prime} 23.5^{\prime \prime E}\right.$; Figure 1), one of the largest intact reserves in the Central Wheatbelt. The number of distinct genets at the study site is unknown. Plants are distributed in distinct stands on the slopes of a granite bornhardt, called Boogin Nop by local Ballardong Noongar people. There, E. caesia occurs in dense thickets with other woody species (including Hakea petiolaris, Allocasuarina huegeliana, Calothamnus ruprestris and Kunzea pulchella), and as isolated plants in cracks in the granite (Figure 2).

\section{Mapping and sample collection}

To accurately assess population size, pollen dispersal distances and spatial genetic structure, a Trimble GeoExplorer differential GPS (Digital Mapping Solutions, Perth, WA, Australia) was used to obtain global positioning system (GPS) coordinates of each plant to an accuracy of $<1 \mathrm{~m}$. E. caesia has extensive asexual reproduction and stems were recorded as comprising a single plant if they arose from a common lignotuber. Leaf samples were collected from a single stem for most plants and from multiple stems of larger plants where lignotuber degradation prevented visual identification of individual genets. Thus, the number of samples collected for genetic analysis was larger than the estimated population size, with a total of 412 samples. Leaf samples were stored fresh in individual zip-lock bags before DNA extraction. A total of 72 fruits (12 per maternal plant) representing the products of the 2012/2013 flowering period were collected from each of 6 trees and dried until the seeds were released. A randomly selected sample of 16 seeds from each fruit were germinated on agar under a $20^{\circ} \mathrm{C}$ day/night cycle. Some seeds failed to germinate and therefore final sample sizes were uneven across the 6 families, with final seed numbers ranging from 12 to 61 seeds per family. Maternal plants were selected to allow investigation of pollen flow into the main summit stand from smaller peripheral stands, and investigation of pollen flow among plants in the summit stand. Within the summit stand, widely spaced plants were selected as maternals to ensure that maternal plants did not comprise a single clonal patch. Generally low capsule numbers per plant across the population constrained the number of maternal plants that were suitable for inclusion in the study. 

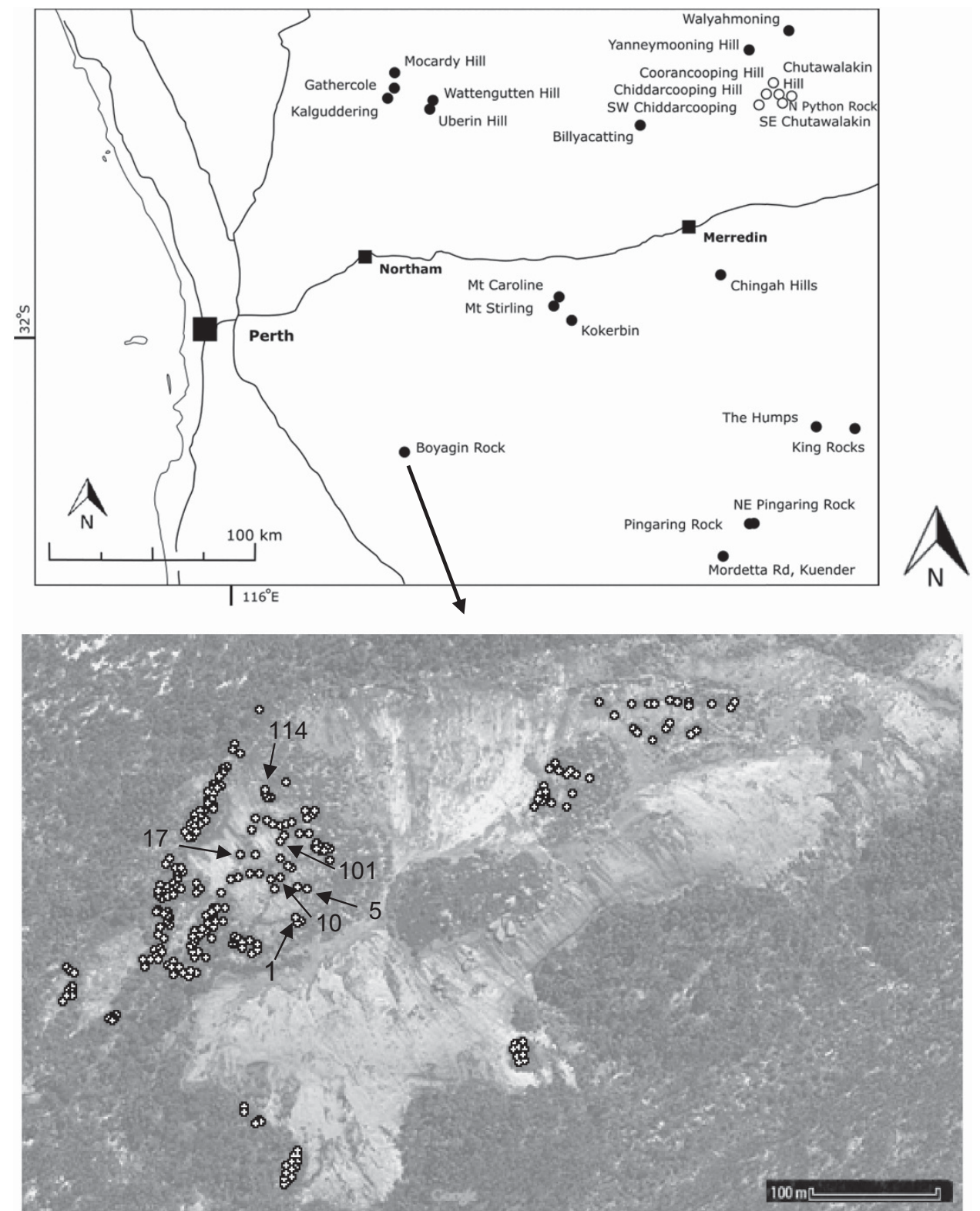

Figure 1 Distribution of Eucalyptus caesia subsp. caesia (closed circles) and E. caesia subsp. magna (open circles) in the Central Wheatbelt of Western Australia, and location of sampled plants at the study site in Boyagin Nature Reserve (32 $28^{\prime} 21.0^{\prime \prime} \mathrm{S}, 116^{\circ} 52^{\prime} 23.5^{\prime \prime}$ ), generated using Google Earth imagery (2014). Arrows indicate trees from which seeds were collected for paternity analysis. Locations of $E$. caesia populations are based on on-ground survey by SD Hopper and Western Australian Herbarium records.

\section{Microsatellite genotyping}

Genomic DNA was extracted from $2 \mathrm{~cm}^{2}$ of adult leaf tissue and from entire seedlings, harvested $1-2$ weeks after germination, using a CTAB (cetyl trimethyl ammonium bromide) extraction method modified from Doyle and Doyle (1987). DNA was extracted from all adult leaf samples $(n=412)$ and 196 seedlings. Because of germination failure of some seeds, final progeny sample numbers were not even across the six families.

Microsatellite loci were amplified using nine primer pairs developed in other eucalypts (EGM25, EGM30, EGM47, EGM14, EGM12, EGM34, EGM35, EMBRA10 and EMBRA7) (Steane et al., 2001; Bradbury et al., 2013a) using the QIAGEN Multiplex PCR Kit (QIAGEN, Venio, Limburg, The Netherlands) as per the manufacturer's instructions. PCR conditions were as follows: $95^{\circ} \mathrm{C}$ for $5 \mathrm{~min}$, then 30 cycles of $95^{\circ} \mathrm{C}$ for $30 \mathrm{~s}, 58^{\circ} \mathrm{C}$ for $1 \mathrm{~min} 30 \mathrm{~s}$ and $72{ }^{\circ} \mathrm{C}$ for $30 \mathrm{~s}$, followed by $60^{\circ} \mathrm{C}$ for $30 \mathrm{~min}$. A total of 30 microsatellite primer pairs were tested for amplification in E. caesia. The final panel of markers were selected based on consistent amplification and scorability in combination with polymorphism, and consisted of three multiplex mixes: group A (EGM35, EMBRA10 and EMBRA7), group B (EGM12 and EGM34) and group C (EGM25, EGM30, EGM47 and EGM14). To optimise amplification peaks, the concentrations of EMBRA10 and EMBRA7 were increased from 2 to 3 and $4 \mu \mathrm{m}$, respectively, and the concentration of EGM35 was reduced to $0.5 \mu \mathrm{m}$.

Amplified product was visualised with an automated 3500 Genetic Analyzer with $10 \mu \mathrm{l} \mathrm{Hi-Di} \mathrm{Formamide} \mathrm{and} 0.3 \mu \mathrm{l} 500$ LIZ size standard (Applied Biosystems, Foster City, CA, USA). Alleles (sized base pairs) were scored manually using Geneious 7.1.4 (Drummond et al., 2011). The database was checked for typing errors by using GenAlEx V6.5 (Peakall and Smouse, 2006, 2012) to generate a list of alleles and by double-checking electropherogram profiles of rare alleles. Positive and negative controls were included in each batch of samples, and randomly chosen individuals (2 samples for each 96-well plate) were genotyped in duplicate to confirm 

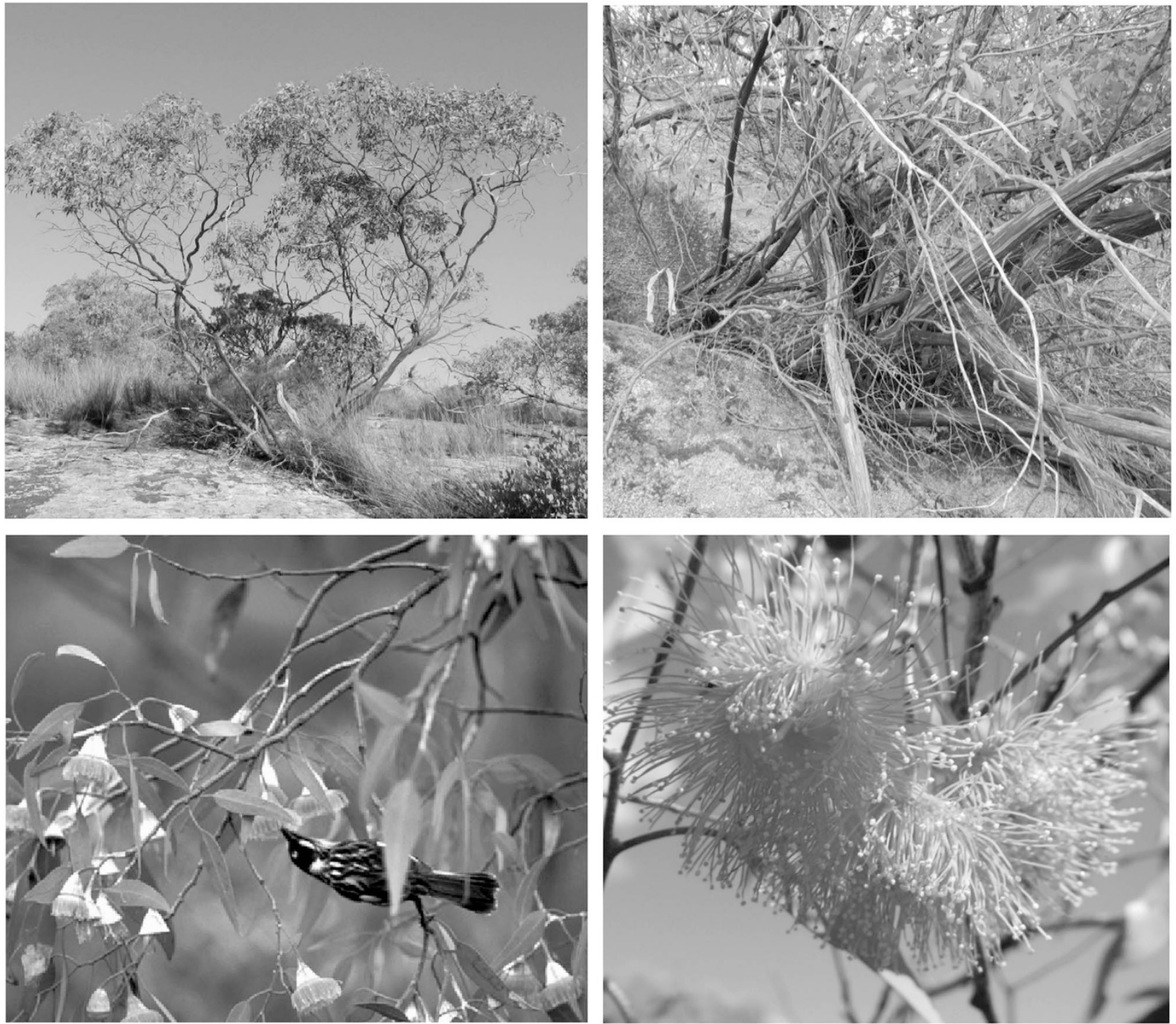

Figure 2 Eucalyptus caesia subsp. caesia growing on slopes of a granite bornhardt in Boyagin Nature Reserve, Western Australia. Photos shown include a single multi-stemmed plant (top left), a New Holland honeyeater foraging for nectar (bottom left; photo by SD Hopper), E. caesia flowers (bottom right) and multiple stems comprising a single multilocus genotype (top left). Photos are by $\mathrm{N}$ Bezemer unless otherwise indicated.

repeatability of allele scoring. The final genetic database was double checked manually. We performed a manual check to confirm that all progeny had at least one maternal allele at each locus.

\section{Population size and genetic diversity}

Some of the 412 sampled stems were expected to be ramets of the same genet because of repeat sampling of larger plants. Replicate multilocus genotypes (MLGs) in the data set were thus identified using the identity analysis function in CERVUS V3.0 (Kalinowski et al., 2007) and all subsequent analyses conducted using the condensed subset $(n=203)$ of the original adult genotypic database $(n=412)$ from which duplicated MLGs were removed.

To assess genetic diversity in the adult cohort, $N$ (number of alleles), $N_{\mathrm{e}}$ (effective number of alleles), $H_{\mathrm{E}}$ (expected heterozygosity), $H_{\mathrm{O}}$ (observed heterozygosity) and $F$ (fixation index) were calculated. The frequency of alleles at each locus was calculated for adults and progeny and significant differences tested for using proportions tests in R (R Core Team, 2014). All diversity statistics were calculated using GenAlEx V6.5 (Peakall and Smouse, 2006, 2012)

\section{Mating system}

Multilocus outcrossing rate $\left(t_{\mathrm{m}}\right)$, biparental inbreeding $\left(t_{\mathrm{m}}-t_{\mathrm{s}}\right)$ and multilocus correlation of paternity $\left(r_{\mathrm{p}}\right)$ were estimated using MLTR (Ritland, 2002). Variance estimates were calculated based on 1000 bootstraps. Resampling was conducted at the family level, rather than for individuals within families, because actual mating system parameters varied between families. Multilocus outcrossing rate is an estimate of the proportion of outcrossed progeny produced by a single maternal parent, or by the population as a whole, in which outcrossing events include mating between relatives and unrelated individuals. Measures of single-locus outcrossing rate differ in that only mating between unrelated individuals is considered an outcrossing event. The difference between the two estimates $\left(t_{m}-t_{s}\right)$ thus provides a measure of the frequency of mating events between close relatives (Ritland, 2002). Correlated paternity is a measure of the proportion of pairs of outcrossed siblings that are full siblings, as opposed to half siblings.

\section{Paternity assignment}

Paternity assignment was conducted by categorical allocation in CERVUS v3.0.3 (Kalinowski et al., 2007). Logarithm of odds (LOD) scores were 
calculated for all sampled plants, as every reproductive individual in the population is a potential sire. Confidence in assignments was measured as the difference in LOD scores $(\Delta)$ between the candidate sire with the highest score and the candidate sire with the second highest score. Strict confidence levels were set at $95 \%$ and relaxed confidence levels at $80 \%$. Where multiple candidate sires remained nonexcluded, likelihood was used to statistically distinguish candidate sires. Where progeny-sire matches did not meet confidence thresholds, but had LOD scores of $\geqslant 3.0$, paternity was assigned to the most likely sire (Slate et al., 2000).

Paternity assignment was used to calculate the realised outcrossing rate, multiple paternity per capsule and per tree and realised pollen dispersal distances. Distributions of realised mating and potential mating under random pollination were tested using the Kolmogrov-Smirnov test and proportions tests for each $20 \mathrm{~m}$ increment, and overall . Distances between maternals and potential sires represent a theoretical distribution of random mating and were calculated by taking the mean distance between each maternal and all other plants, and then averaging those values for each incremental $20 \mathrm{~m}$ distance class. Thus, the proportion of potential mating events reflects the number of maternal/potential sire pairs that occur within each distance class. To standardise for population size and density, realised pollen dispersal was also plotted against ranked distance between maternals and all potential sires. Ranked distance was calculated by assigning plant pairs a value from 1 to 202, representing the nearest and most distant neighbour, respectively. The resulting distribution was tested for kurtosis $(K)$ using the kurtosis function in R. Negative kurtosis indicates a flat data distribution (platykurtosis), positive kurtosis indicates a peaked distribution (leptokurtosis) and zero kurtosis indicates normal distribution. A simple linear regression analysis was applied in $\mathrm{R}$ to test whether the proportion of outcross mating declined linearly with ranked distance, following the approach of Krauss et al. (2009).

\section{Genetic structure and stand differentiation}

Matrices of genetic and geographic distances between all plant pairs were generated in GenAlEx V6.5 and their relationship tested using a Mantel test for Matrix Correspondence. Genetic distance was calculated using the pairwise, individual-by-individual genetic distance matrix for codominant data option in GenAlEx. In addition, the genetic correlation between individuals as a function of spatial distance was assessed using the spatial autocorrelation analysis. The analysis was performed using distance classes ranging from 5 to $50 \mathrm{~m}$, and evenly spaced distance classes of $20 \mathrm{~m}$ selected for the final analysis as this distance was deemed suitable given the maximum distance between plants $(380 \mathrm{~m})$. A correlation coefficient $(r$, where $0=$ random distribution of genotypes) was calculated for all pairs of individuals within each distance class, and means and errors plotted on a correlogram. To define significance limits,
95\% confidence intervals of $r$ were generated by randomising the data and by bootstrapping. Spatial autocorrelation analysis was performed using GenAlEx V6.5.

Genetic clustering of individual MLGs was assessed using the program STRUCTURE (Pritchard et al., 2000). Although STRUCTURE has been commonly applied to describe genetic relationships among populations (Kalinowski, 2011), it is an individual-based analysis and is therefore suitable to test for the presence of genetic clustering within populations. A model assuming no prior groupings was selected, and different numbers of genetic clusters $(K)$ tested, ranging from $K=1$ to $K=5$. The option of correlated allele frequencies was selected as this setting is recommended where either population structure, or the ability to detect it, is subtle (Falush et al., 2003). A burn-in period of 100000 was used, followed by $10^{6}$ Markov chain Monte Carlo replicates, with 50 iterations for each $K$ value. The number of $K$ that best fit the data was selected by comparing $\Delta K$ values (Evanno et al., 2005) generated using the Python program STRUCTURE Harvester (Earl, 2012). Population genetic structure indices including $F_{\mathrm{ST}}, G_{\mathrm{ST}}$, Nei's standardised and Hederick's standardised $G_{S T}^{\prime}, G^{\prime \prime}{ }_{S T}$ and $D_{\mathrm{EST}}$ were calculated in GenAlEx for the optimal $K$ clusters from STRUCTURE. To assess whether plants in different genetic clusters were randomly or nonrandomly distributed, maps showing the location of individuals with $\geqslant 60 \%$ inferred membership to any one of the genetic clusters identified by STRUCTURE analysis were generated in R. A principle coordinates analysis based on a matrix of genetic distance of MLGs was conducted in GenAlEx as an independent assessment of genetic clustering.

\section{RESULTS}

\section{Genetic diversity}

Allelic diversity was low, with three loci having only two alleles (EGM25, EGM47 and EGM14), whereas seven out of nine loci had four or less alleles and two loci (EGM35 and EMBRA7) had seven and nine alleles, respectively (Table 1). The total number of alleles detected across all samples was 37. Observed and expected heterozygosity across loci ranged from 0.28 to 0.79 and from 0.32 to 0.78 , respectively. The fixation index was not significantly different from zero (overall mean $F=0.016$ ( \pm s.e. 0.032$)$ ). There was evidence for deviation from Hardy-Weinberg equilibrium in four loci, but there were no progeny-maternal mismatches, indicating that null alleles did not compromise the results of the paternity analysis. Allele frequencies did not differ markedly between the adult stand and sampled progeny, despite the sampling effect of only six maternals (Supplementary Figure S1). However, five alleles were present in greater frequencies in

Table 1 Genetic variation at each of nine microsatellite loci for unique multilocus genotypes of Eucalyptus caesia subsp. caesia in Boyagin Nature Reserve

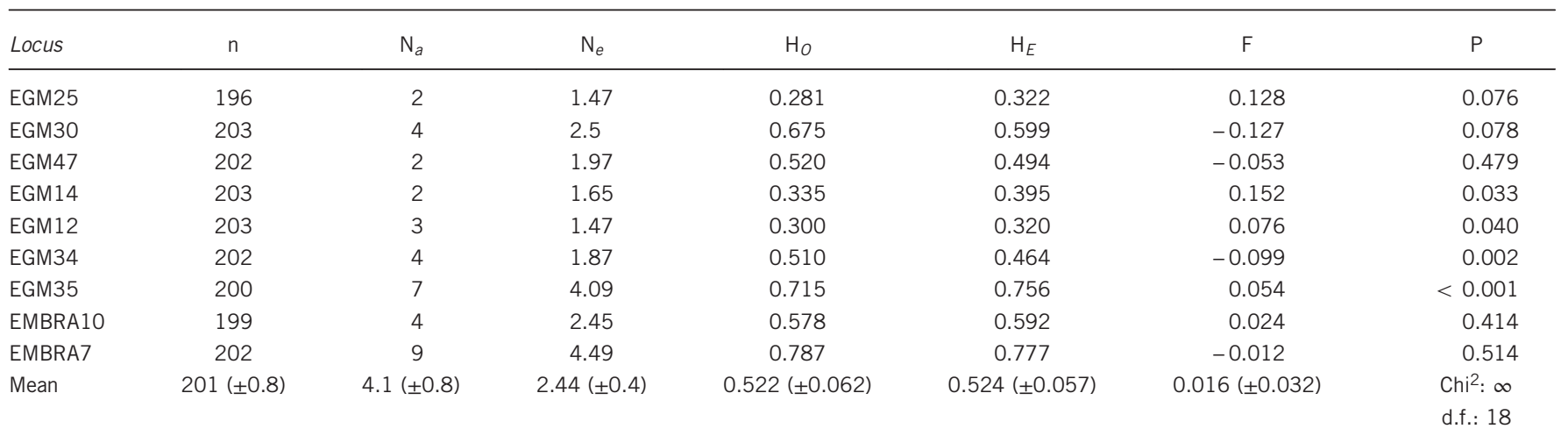


the progeny, whereas three alleles were more common in the adults. In addition, some rare alleles present in the adults were absent in the progeny.

\section{Mating system}

At the population level, multilocus outcrossing rate estimate from MLTR was 0.832 , the estimate of biparental inbreeding was 0.06 and the estimate of correlated paternity was 0.136 (Table 2). Multilocus outcrossing rate estimates for each family ranged from 0.479 to 0.806 , and levels of biparental inbreeding were close to zero.

\section{Paternity assignment}

Out of 196 progeny that were genotyped, 19 were assigned paternity at a $95 \%$ confidence threshold, 32 at $80 \%$ confidence and a most likely sire identified for a further 130 progeny (Supplementary Figure S2). The remaining 15 progeny had multiple potential sires with equal LOD scores, or LOD scores of $<3.0$, and were excluded from all further analyses.

Realised outcrossing rates varied among the 6 families (0.64-0.87; Table 2). The mean number of different sires per fruit ranged from 3.5 ( \pm s.e. 0.3$)$ to $6( \pm$ s.e. 1.0$)$, whereas the number of different sires assigned paternity per tree ranged from 9 to 25 . The total number of different sires for all 181 seed across six families was 64 .

\section{Pollen dispersal}

Mating between trees occurred over relatively large distances, given the spatial scale of the study population (Figures 3 and 4). Of 130 outcross pollination events detected by paternity assignment, $74 \%$ occurred between trees $>20 \mathrm{~m}$ apart, $28 \%$ between trees $>60 \mathrm{~m}$ apart and $14 \%$ between trees $>100 \mathrm{~m}$ apart (Figure $4 \mathrm{a}$ ). A large proportion of outcross dispersal events (59 out of 130) occurred between trees 20 to $60 \mathrm{~m}$ apart. There were significant differences between observed and random mating events at 5 out of 11 distance classes (all $P$-values $<0.01)$. Where significant differences occurred, the proportions of observed/random mating events were $0.26 / 0.03$ at $<20 \mathrm{~m}, 0.29 / 0.09$ at $20-40 \mathrm{~m}, 0.03 / 0.14$ at $80-100 \mathrm{~m}, 0.02 / 0.12$ at $100-120 \mathrm{~m}$ and $0.03-$ $/ 0.19$ at $>200 \mathrm{~m}$. Observed mating events were higher than random mating expectations for plants $<40 \mathrm{~m}$ apart, indicating leptokurtic dispersal at this scale. The mean realised pollen dispersal distance was $39.4 \mathrm{~m}$ ( \pm s.e. 3.9$)$ considering all mating events, and $54.8 \mathrm{~m}$ ( \pm s.e. 4.9) considering outcrosses only. The mean distance between maternal plants and all other plants was $120.8 \mathrm{~m}$ ( \pm s.e. 2.5 ). The maximum realised pollen dispersal distance for paternity assignments made at the 95\% confidence threshold, $80 \%$ confidence threshold and at the most likely level were 240, 295 and $236 \mathrm{~m}$, respectively, whereas the distance between maternal plants and their most distant neighbours ranged from 339 to $355 \mathrm{~m}$.

Considering all progeny-sire matches, $91 \%$ of outcross mating events occurred between nonnearest neighbours, and half of all realised outcross pollination events were to plants further away than the 27th nearest neighbour (Figure $4 \mathrm{~b}$ ). There was a significant negative correlation $(R=-0.349, P=0.004)$ between the proportion of outcross events and ranked distance. The proportion of mating events between nearest neighbours relative to nonnearest neighbours remained low when only progeny-sire matches made at 80 and $95 \%$ confidence thresholds were considered, and no significant relationship between these mating events and ranked distance was detected. Negative kurtosis values for both data sets $(K=-0.881$ and -3.11 , respectively) indicate platykurtic frequency distributions.

\section{Genetic structure and stand differentiation}

Genetic structuring of the 203 unique MLGs was evident within patches and across the entire stand. The Mantel test revealed an overall weak but positive relationship between genetic and geographic distance between pairs of plants $(\mathrm{Rxy}=0.222$; $\mathrm{P}$ (Rxy-rand $\geqslant \mathrm{Rxy}$ data $=0.010$ ). Spatial autocorrelation analysis revealed a positive association between genetic correlation and geographic distance up to $70 \mathrm{~m}$, after which no significant positive correlations were observed (Supplementary Figure S3). From STRUCTURE analysis, the number of genetic clusters that best fit the data were $3\left(\Delta K_{3}=150\right.$ and $<30$ for all other $K$ ) (Figure 5 and Supplementary Figure S4). The estimated proportion of membership to each group was 35.3, 29, and $35.6 \%$. There was strong evidence for admixture among groups and admixed individuals were geographically interspersed within the

Table 2 Mating system, multiple paternity and outcrossing rate for Eucalyptus caesia subsp. caesia at Boyagin Nature Reserve, Western Australia

\begin{tabular}{|c|c|c|c|c|c|c|c|c|c|c|c|}
\hline \multirow{3}{*}{$\begin{array}{l}\text { Maternal } \\
\text { tree ID }\end{array}$} & \multirow{3}{*}{$\begin{array}{l}\text { Number of } \\
\text { capsules }\end{array}$} & \multicolumn{5}{|c|}{ MLTR estimates } & \multicolumn{5}{|c|}{ Calculations based on CERVUS results } \\
\hline & & \multirow[t]{2}{*}{$n$} & \multirow[t]{2}{*}{$\mathrm{t}_{m}$} & \multirow[t]{2}{*}{$\mathrm{t}_{m}-\mathrm{t}_{s}$} & \multirow[t]{2}{*}{$r_{p}$} & \multirow[t]{2}{*}{$1 / r_{p}$} & \multicolumn{2}{|r|}{$\mathrm{n}$} & \multicolumn{2}{|c|}{ Number of different sires } & \multirow{2}{*}{$\begin{array}{l}\text { Proportion } \\
\text { outcrossed }\end{array}$} \\
\hline & & & & & & & Seeds & $\begin{array}{c}\text { Mean } \\
\text { seeds/cap. }\end{array}$ & Mean/ cap. & Total/tree & \\
\hline 1 & 9 & 67 & $0.681( \pm 0.064)$ & 0.111 & - & - & 61 & $6.7( \pm 1.0)$ & $4.5( \pm 0.8)$ & 25 & 0.64 \\
\hline 5 & 2 & 13 & $0.479( \pm 0.315)$ & -0.008 & - & - & 12 & $6.0( \pm 0.0)$ & $5( \pm 1.0)$ & 9 & 0.67 \\
\hline 10 & 6 & 35 & $0.806( \pm 0.102)$ & -0.038 & - & - & 33 & $5.5( \pm 1.9)$ & $3.8( \pm 1.2)$ & 18 & 0.77 \\
\hline 17 & 4 & 18 & $0.592( \pm 0.156)$ & -0.032 & - & - & 16 & $4.0( \pm 0.7)$ & $3.5( \pm 0.3)$ & 10 & 0.87 \\
\hline 101 & 5 & 51 & $0.729( \pm 0.069)$ & 0.076 & - & - & 46 & $9.2( \pm 0.4)$ & $6.0( \pm 0.5)$ & 24 & 0.67 \\
\hline 114 & 2 & 14 & $0.709( \pm 0.265)$ & -0.118 & - & - & 13 & $6.5( \pm 0.5)$ & $6.0( \pm 1.0)$ & 10 & 0.87 \\
\hline Pop./combined & 28 & 196 & $0.832( \pm 0.05)$ & $0.060( \pm 0.025)$ & $0.136( \pm 0.048)$ & 7.3 & 181 & $6.5( \pm 0.6)$ & $4.6( \pm 0.3)$ & 64 & 0.72 \\
\hline
\end{tabular}

Abbreviations: cap., capsule; pop., population; $r_{\mathrm{p}}$, multilocus correlation of outcrossed paternity; $1 / r_{\mathrm{p}}$, effective number of mates; $t_{\mathrm{m}}$, multilocus outcrossing rate; $t_{\mathrm{m}}-t_{\mathrm{s}}$, biparental inbreeding estimate.

MLTR variance estimates were calculated from 1000 bootstraps and are shown in parentheses. Multiple paternity values were calculated on the basis of paternity assignments made in CERVUS; s.e. values are shown in parentheses. 

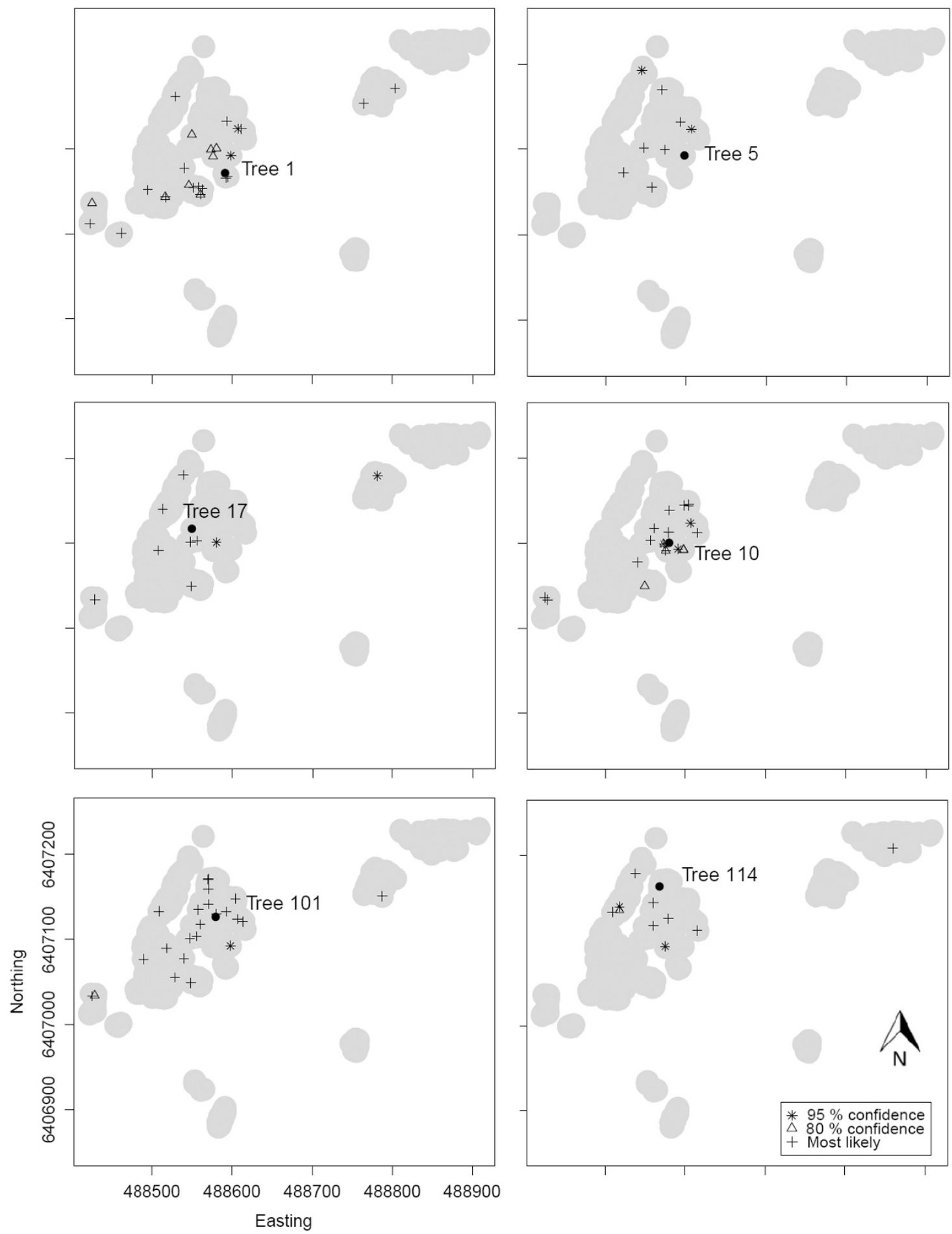

Figure 3 Distribution of outcross pollen donors for six Eucalyptus caesia subsp. caesia located on the summit of a granite bornhardt in Boyagin Nature Reserve, Western Australia (GDA 94, Zone 50). Axis values are UTM easting ( $x$ axis) and northing ( $y$ axis). Data are based on the results of a paternity assignment ( $n=39$ (Tree 1), 8 (Tree 5), 26 (Tree 10), 14 (Tree 17), 31 (Tree 101) and 12 (Tree 114)) conducted in CERVUS.

stand. Estimates of genetic distance between these clusters were exceptionally high given the spatial scale of the study site of $\sim 12$ hectares (Table 3 ). The percentage of variation explained by the first three axes in the principal coordinates analysis were 12.19 , 10.40 and $9.88 \%$. Genetic clustering was evident in plots of principle coordinates 1 vs 2 and 1 vs 3 (Figure 5). The STRUCTURE clusters 1 and 3 were separated by principle coordinate 3 and STRUCTURE cluster 2 separated from clusters 1 and 3 by principle coordinate 1 .

\section{DISCUSSION}

Adaptations favouring frequent cross-pollination among plants may counteract or reduce the predicted genetic effects associated with inbreeding and genetic drift in small isolated populations (Ellstrand 


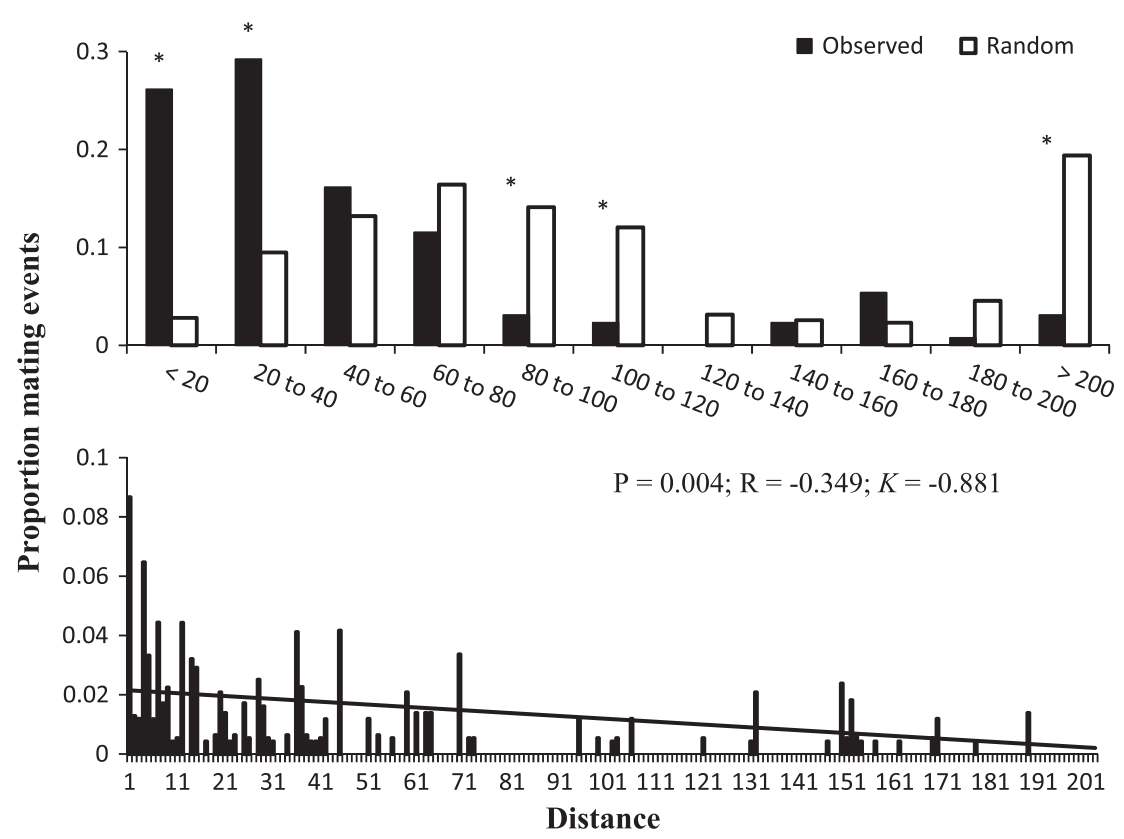

Figure 4 Proportion of realised outcross mating events with distance, showing (a) observed and random outcross pollination events with geographic distance (m) between plant pairs and (b) proportion of mating events with ranked distance between plant pairs. Realised mating events are based on the results of a paternity assignment of seeds $(n=130)$ collected from 6 Eucalyptus caesia subsp. caesia in Boyagin Nature Reserve, Western Australia. Potential mating events are the distances between maternal trees and all potential sires. ${ }^{*}$ Significant differences $(P<0.01)$ between observed and potential mating events.

and Elam, 1993). Eucalyptus caesia has persisted for an extremely long period, possibly since the Pliocene, as naturally small, fragmented and genetically isolated populations (Moran and Hopper, 1983; Byrne and Hopper, 2008). As documented previously (Moran and Hopper, 1983) and in the present study, genetic diversity in E. caesia is extremely low compared with other eucalypts, suggesting genetic drift as a significant evolutionary force (Byrne and Hopper, 2008). Wide outcrossing and/ or purging of deleterious mutations causing inbreeding depression, however, may buffer the negative impacts of genetic drift. Our application of molecular markers for the assignment of paternity in E. caesia has confirmed predictions of wide within-stand outcrossing, high multiple paternity and a departure from a leptokurtic pollen dispersal distribution that are, at least in part, a consequence of pollination by highly mobile nectar-feeding birds. Optimal foraging theory, although relevant to many plant species, may not always apply when birds make a substantial contribution to pollination. Aggressive interactions among highly mobile nectarivorous birds may frequently lead to a departure from optimal foraging and result in high pollen carryover (Mitchell et al., 2013).

We suggest that pollination by highly mobile nectar-feeding birds increases the resilience of naturally fragmented and genetically insular plant populations by buffering genetic erosion. In this sense, our results extend the argument that predictions of genetic decline in recently fragmented populations are generally not supported by empirical evidence (Kramer et al., 2008) to include historically fragmented populations such as the Boyagin stand of E. caesia. Resilience to recent fragmentation is expected to be greater for species with highly mobile pollinators as a result of increased genetic connectivity among isolated stands (Byrne et al., 2007; Ismail et al., 2012; Breed et al., 2013). For example, in the bird-pollinated Eucalyptus incrassata regular long-distance pollen flow between fragments may mitigate the effects of genetic drift (Breed et al., 2012). Adaptations favouring pollen dispersal by highly mobile animals may be equally important in mitigating the loss of genetic diversity within stands.

Our results did not, however, support the predictions of weak spatial genetic structure in the adult stand expected from wide dispersal of pollen. Rather, we found evidence for moderate spatial genetic structure, with the stand comprising three distinct genetic clusters that displayed a marked degree of geographic overlap. We suggest that this spatial genetic structure reflects a life-history strategy of extreme individual plant longevity through clonality, combined with extremely rare large-scale recruitment events that, in mallee eucalypts, typically occur when environmental variables such as climate and soil moisture are favourable and coincide with disturbance such as fire (Wellington and Noble, 1985). With the exception of recent recruitment of $E$. caesia at the study site and at Chidaarcooping Nature Reserve following wildfires, on-ground surveys of all known stands show an absence of recruitment for at least 50 years, possibly much longer (SD Hopper, personal observation). Thus, the rate of generational change is expected to be extremely slow for natural populations of E. caesia. Ultimately, extreme longevity combined with the genetic consequences of wide outcrossing as a result of bird pollination are likely to be important for the persistence of genetic variation in small, geographically isolated stands of E. caesia. This conclusion is in accordance with the James Effect Hypothesis (Hopper, 2009; Hopper et al., 2016) that predicts that mechanisms conserving heterozygosity will feature prominently in rare, localised endemics, as a result of prolonged genetic isolation.

Genetic consequences of multiple mating and wide pollen dispersal Correlated paternity in E. caesia $\left(r_{\mathrm{p}}=0.136\right)$ was markedly lower than reported in generalist-pollinated plants, such as Eucalyptus marginata (0.75; Millar et al., 2000) or insect-pollinated Acer macrophyllum (0.39; Iddrisu and Ritland, 2004) and Acacia melanoxylon (0.40; Muona et al., 1991), and fell within the generally low range of correlated paternity values reported for other bird-pollinated plants such as 
Eucalyptus rameliana (0.26; Sampson, 1998), E. incrassata (0.16; Breed et al., 2012) and Banksia hookeriana (0.037; Krauss et al., 2009). In contrast, multiple paternity, although high, was lower than other plants with bird pollination systems (Llaurens et al., 2008; Krauss et al., 2009). Although multiple paternity is a common feature of plants with significant genetic/evolutionary benefits (Jennions and
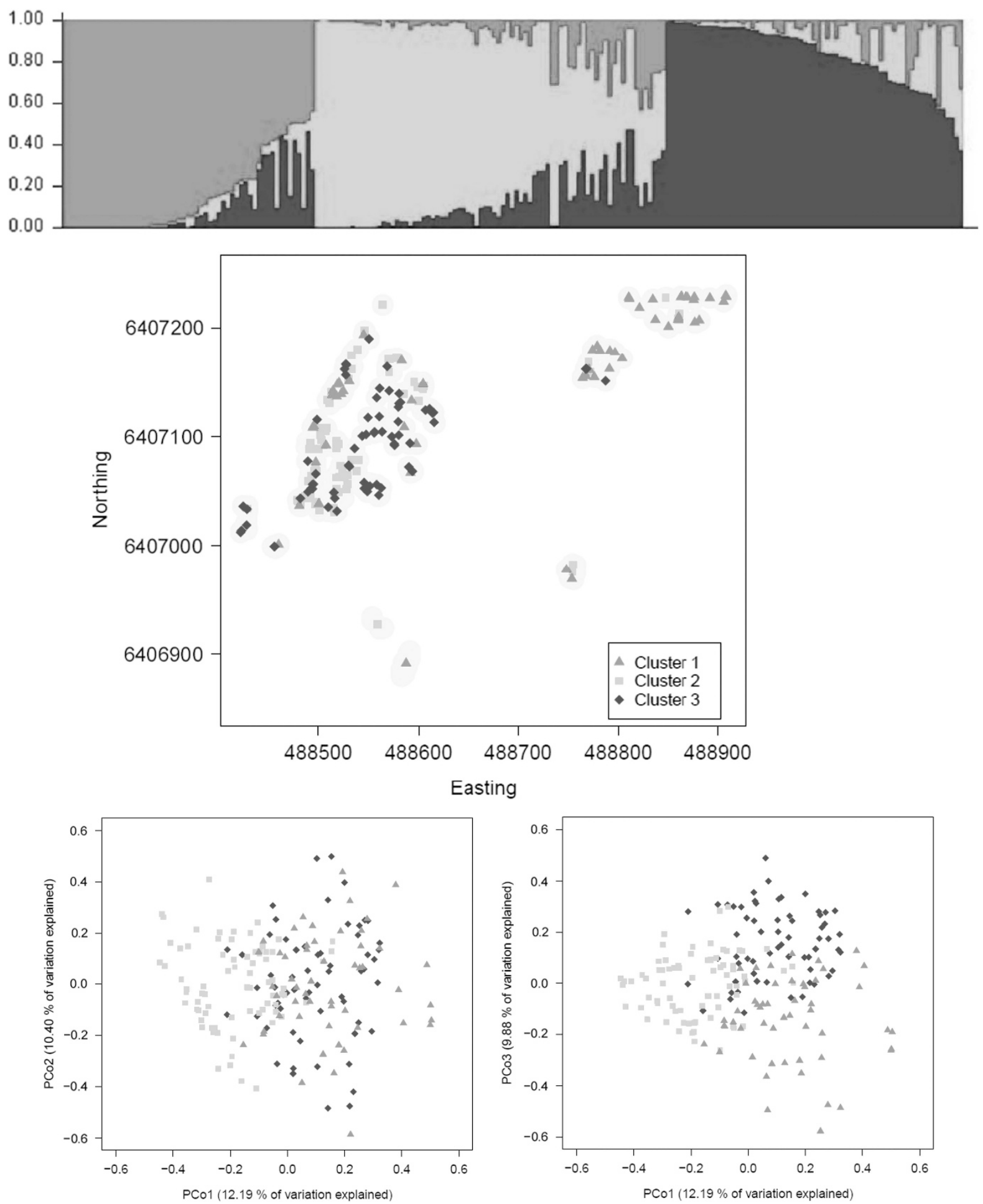

Figure 5 Genetic differentiation in a stand of Eucalyptus caesia subsp. caesia located in Boyagin Nature Reserve, Western Australia (GDA 94, Zone 50H), showing (a) assignment of individuals to genetic clusters based on maximum likelihood analysis in STRUCTURE, (b) geographic location of individuals with $\geqslant 60 \%$ inferred membership to one of three clusters and (c) principle coordinates analysis (PCoA) plots of axes 1 vs 2 and 1 vs 3 and the total variation explained. 
Table 3 Genetic differentiation between inferred clusters in a stand of Eucalyptus caesia subsp. caesia located in Boyagin Nature Reserve, Western Australia

\begin{tabular}{lllllll} 
Cluster & $\mathrm{F}_{S T}$ & $\mathrm{G}_{S T}$ & $\mathrm{G}^{\prime}{ }_{S T} N$ & $\mathrm{G}^{\prime}{ }_{S T} H$ & $\mathrm{G}^{\prime \prime}{ }_{S T}$ & $\mathrm{D}_{E S T}$ \\
\hline 1 vs 2 & 0.054 & 0.050 & 0.095 & 0.163 & 0.203 & 0.119 \\
1 vs 3 & 0.053 & 0.050 & 0.095 & 0.139 & 0.180 & 0.093 \\
2 vs 3 & 0.059 & 0.056 & 0.105 & 0.161 & 0.205 & 0.111 \\
\hline
\end{tabular}

Petrie, 2000; Pannell and Labouche, 2013), the mechanisms through which it arises can vary drastically across species. For example, in birdpollinated eucalypts, low flowering intensity of individuals and low population density of flowering plants may restrict bird movement and lead to the use of the same pollen sources in independent pollination events (Sampson, 1998). Conversely, low flowering intensity of individual plants or highly asynchronous flowering of the population as a whole could also lead to reduced kinship by forcing pollinators to move more frequently between plants in order to satisfy nectar or pollen requirements (Phillips et al., 2014).

Low correlated paternity and high multiple paternity in our study could reflect extensive pollen carryover by highly mobile bird pollinators (Mitchell et al., 2013). Indeed, high sire diversity in the hummingbird-pollinated Ipomopsis aggregata is attributed to extensive pollen carryover, in contrast to the insect-pollinated Mimulus ringens with reduced sire diversity and restricted pollen carryover (Mitchell et al., 2013). Here, it is important to note that multiple pollinator visits to $M$. ringens flowers increases the number of mates (Karron et al., 2006). Future studies could thus expand the findings of Mitchell et al. (2013) by contrasting the influence of single and multiple visits by different pollinator groups on multiple paternity and sire diversity. Whether high sire diversity in E. caesia results from simultaneous or sequential polyandry, and the influence of different pollinator groups, requires experimental testing. High multiple paternity may also arise through density-dependent effects. For example, Arabidopsis halleri has exceptionally high multiple paternity (average 22.4 sires per 26.7 offspring per maternal) despite clonality and insect pollination, as a result of extremely high population density (Llaurens et al., 2008). In contrast to the largely density-dependent polyandry observed in plants such as A. halleri, we suggest that multiple mating in E. caesia is coupled with a high diversity of sires because of frequent movement of honeyeaters between widely spaced plants. From an evolutionary perspective, multiple mating with a diverse array of plants may reduce pollen limitation (Knight et al., 2005), promote pollen competition (Delph and Havens, 1998) and lead to the production of a more genetically variable progeny (Karron and Marshall, 1990) or progeny cohorts with increased survival rates (Breed et al., 2014), potentially increasing the genetic resilience of small, isolated populations such as E. caesia at Boyagin Reserve.

The platykurtic distribution of pollen dispersal distances found in $E$. caesia is a departure from the typically leptokurtic dispersal distribution predicted for animal-pollinated plants (Harder and Barrett, 1996). In E. caesia, there was no significant difference between observed and random mating events between plants 40-80 and 120-200 m apart, indicating that the likelihood of mating was influenced by, but not strongly dependent on, distance for plants $>40 \mathrm{~m}$ apart. Conversely, there was a significantly higher proportion of observed to potential mating events between plants $<40 \mathrm{~m}$ apart, indicating a frequency of short-distance pollen dispersal in excess of random mating expectations. Realised outcrossing rates of $0.64-0.87$ indicated that selfpollination is not uncommon in E. caesia. However, studies in other eucalypts with mixed mating systems suggest post-germination selection against inbred progeny should remove most if not all selfed plants from the standing population (James and Kennington, 1993; Harder and Potts, 1997).

With respect to the frequent short-distance pollen dispersal we detected, our results differed with those of the honeyeater-pollinated B. hookeriana, where mating between near neighbours occurred less frequently and the overall pollen dispersal distribution was panmictic (Krauss et al., 2009). This may reflect differences in the behaviour or composition of honeyeater species between sites because of variation in resource availability (Mac Nally et al., 2005), or different spatial distributions of plants, or a greater contribution to pollination from insects. In eucalypt species such as E. globulus, pollination by insects may result in predominantly short-distance pollen dispersal, whereas flower visitation by birds or bats is more likely to explain longer dispersal events (Southerton et al., 2004). We therefore predict that bird pollination, rather than insect pollination, is responsible for the long dispersal curve and high frequency of mating events between widely spaced plants in the Boyagin stand of E. caesia. Whether insects or birds or both groups are implicated frequent mating between plants $<40 \mathrm{~m}$ is uncertain and requires investigation.

The relative contribution of birds and insects such as the introduced honeybee to mating and pollen dispersal in E. caesia is unknown. Following their introduction to Australia ca. 150 years ago, introduced honeybees are now ubiquitous across the SWAFR, and are efficient pollinators of some plants but disruptive to others (Paton, 1993; Yates and Ladd, 2004). Our field observations of E. caesia indicate that although honeybees are frequent visitors to plants and consume substantial amounts of nectar, movement between plants is rare. Similarly, nearly $10 \mathrm{~h}$ of honeybee observations saw no movement between Callistemon rugulosus plants, whereas territorial New Holland Honeyeaters (Phylidonyris novaehollandiae) moved between plants on average 7.3 times per hour (Paton, 1993). These results may be biased because of the difficulty in following the movements of small insects, particularly considering that honeybees do forage over extensive areas (Visscher and Seeley, 1982). Honeybees often fail to contact the reproductive structures of bird-adapted plants, such as E. stoatei (Hopper and Moran, 1981) and Banksia menziesii (Ramsey, 1988), making their effectiveness as pollinators of E. caesia questionable, particularly as the flowers are large enough to permit access to nectaries without contacting the stigma. A pollinator exclusion experiment that allows insect access to flowers is required to resolve whether insects pollinate E. caesia, and whether short-distance pollen dispersal among E. caesia results predominantly from the activity of birds or insects. Studies that compare patterns of plant visitation and empirically test the extent of pollen carryover by insects and birds within a single plant species would be both novel and informative (Mitchell et al., 2013).

\section{Spatial genetic structure and geographic interspersion of genetic clusters}

Given the wide realised pollen dispersal and small spatial extent of the study population, genetic differentiation of the three genetic clusters recognised by STRUCTURE was surprisingly high. Indeed, the genetic differentiation we observed falls within the range of values reported for geographically isolated populations, or across species' ranges, in the southwest region and that are attributed to isolation by distance effects (Bradbury et al., 2013b; Nistelberger et al., 2015). Alternatively, high population genetic differentiation may reflect colonisation or recruitment history (Jones et al., 2006; Pardini and Hamrick, 2008). For example, in Albizia julibrissin (Fabaceae), different genetic groups were 
spatially and temporally clustered and corresponded to episodes of recruitment (Pardini and Hamrick, 2008). In contrast, the three genetic clusters of $E$. caesia were interspersed rather than aggregateda pattern that we suggest reflects gradual erosion of spatial genetic structure through extensive pollen dispersal and subsequent recruitment of widely outcrossed individuals, and a high survivorship of adult plants through lignotuber resprouting. On the other hand, weak spatial structuring of genetic groups could also reflect long-distance seed dispersal or the historical effect of a seed shadow (Jones et al., 2006). Spatial autocorrelation analysis indicated genetic patch sizes of $70 \mathrm{~m}$ in the study population that may partially reflect greater seed dispersal distances than expected for eucalypts as seeds may be transported downslope by wind or water (Byrne and Hopper, 2008). Empirical tests of seed dispersal distances on granite rocks and canopy and soil-seedbank longevity of E. caesia are required.

Extreme longevity of individual plants, facilitated by asexual reproduction, is likely to influence spatial genetic structure in E. caesia. We found a mean of 7 stems per unique MLG, and the largest putative clonal patch comprised 55 stems over an area $8.8 \mathrm{~m}$ wide and $11.5 \mathrm{~m}$ long. Such patches of E. caesia may be thousands of years old and among the oldest known eucalypts (Smith et al., 2003). The relative contribution of recruitment history, seed/pollen dispersal and extensive clonal reproduction on the fine-scale spatial genetic structure of E. caesia requires further study. Following a recent fire that has triggered seedling recruitment at the study site, an opportunity exists to test the hypothesis that geographic interspersion of genetic clusters results from recruitment of highly outcrossed individuals resulting from extensive pollen dispersal. This episode also presents an opportunity to assess the degree to which extensive asexual reproduction in between rare episodes of sexual reproduction contributes to accentuated persistence of E. caesia.

\section{Conservation implications}

Our study represents one of the most detailed analyses of mating and pollen dispersal in a bird-pollinated plant in a natural landscape. We extended the findings of recent studies in banksias (Krauss et al., 2009; Ritchie and Krauss, 2012) by indicating that non-leptokurtic pollen dispersal and high multiple paternity, most likely as a result of extensive pollen dispersal by honeyeaters, may characterise birdpollinated plants. However, disturbances such as habitat fragmentation may disrupt pollinator visitation, leading to reduced cross-pollination, predominantly near neighbour mating and high correlated paternity in bird-pollinated plants (Coates and Hamley, 1999; Llorens et al., 2012; Coates et al., 2013). The frequency of honeyeater movement among plants may vary with plant population size (Yates et al., 2007; Phillips et al., 2014), and pollinator behavioural characteristics may vary with a range of factors such as population shape and level of isolation (Llorens et al., 2012). Overall, the results of our study suggest that genetic erosion leading to population decline is not necessarily inevitable in small, genetically isolated populations of bird-pollinated plants. Rather, wide pollen dispersal within stands by honeyeaters could maintain or even enhance genetic diversity within stands even when population diversity remains intrinsically low. Small populations of naturally or recently fragmented bird-pollinated plants-characteristics of many of the $40 \%$ of threatened species in the SWAFR that are pollinated by vertebrates - should be considered viable and remain a high conservation priority. Although wide outcrossing occurred in the study population, the very strong genetic differentiation evident among geographically isolated populations (Byrne and Hopper, 2008) indicates that the protection of each E. caesia population is necessary to retain species-level genetic diversity.

\section{DATA ACCESSIBILITY}

Sampling locations and microsatellite genotypes are available from the Dryad Digital Repository: http://dx.doi.org/10.5061/dryad.43rv3.

\section{CONFLICT OF INTEREST}

The authors declare no conflict of interest.

\section{ACKNOWLEDGEMENTS}

We thank Dr Janet Anthony for assistance and advice in the laboratory and Karl Bischoff for assistance with fieldwork. The project was funded by an Australian Research Council Grant to SDH, SLK and RDP (DP140103357) for work on the evolution and conservation consequences of promiscuity in plants pollinated by vertebrates. SDH was also supported by a Discovery Outstanding Researcher Award attached to this grant, and by grants from the Great Southern Development Commission and the Jack Family Trust.

\section{AUTHOR CONTRIBUTIONS}

$\mathrm{N}$ Bezemer designed and performed the research, analysed the data and wrote the paper. SL Krauss, RD Phillips, DG Roberts and SD Hopper supervised the research, contributed to experimental design, provided advice on statistical and laboratory analyses and reviewed drafts of the paper.

Bradbury D, Smithson A, Krauss SL (2013a). Development and testing of new genehomologous EST-SSRs for Eucalyptus gomphocephala (Myrtaceae). Appl Plant Sci 1: 1300004 .

Bradbury D, Smithson A, Krauss SL (2013b). Signatures of diversifying selection at ESTSSR loci and association with climate in natural Eucalyptus populations. Mol Ecol 22: 5112-5129.

Breed MF, Christmas MJ, Lowe AJ (2014). Higher levels of multiple paternities increase seedling survival in the long-lived tree Eucalyptus gracilis. PLoS One 9: e90478.

Breed MF, Ottewell KM, Gardner MG, Marklund MHK, Dormontt EE, Lowe AJ (2013). Mating patterns and pollinator mobility are critical traits in forest fragmentation genetics. Heredity 115: 108-114.

Breed MF, Ottewell KM, Gardner MG, Marklund MHK, Stead MG, Harris JBC et al. (2012). Mating system and early viability resistance to habitat fragmentation in a bird-pollinated eucalypt. Heredity 115: 100-107.

Brooker MIH, Hopper SD (1982). New subspecies in Eucalyptus caesia and in E. crucis (Myrtaceae) of Western Australia. Nuytsia 4: 113-128.

Byrne M, Elliott CP, Yates CJ, Coates DJ (2007). Extensive pollen dispersal in a birdpollinated shrub, Calothamnus quadrifidus, in a fragmented landscape. Mol Ecol 16: $1303-1314$.

Byrne M, Elliott CP, Yates CJ, Coates DJ (2008). Maintenance of high pollen dispersal in Eucalyptus wandoo, a dominant tree of the fragmented agricultural region in Western Australia. Conserv Genet 9: 97-105.

Byrne M, Hopper SD (2008). Granite outcrops as ancient islands in old landscapes: evidence from the phylogeography and population genetics of Eucalyptus caesia (Myrtaceae) in Western Australia. Biol J Linn Soc 93: 177-188.

Coates DJ, Hamley VL (1999). Genetic divergence and the mating system in the endangered and geographically restricted species, Lambertia orbifolia Gardner (Proteaceae). Heredity 83: 418-427.

Coates DJ, Williams MR, Madden S (2013). Temporal and spatial mating-system variation in fragmented populations of Banksia cuneata, a rare bird-pollinated long-lived plant. Aust J Bot 61: 235-242.

Delph LF, Havens K (1998). Pollen competition in flowering plants. In: Birkhead T, Moller A (eds). Sperm Competition and Sexual Selection. Academic Press: San Diego, CA. pp 149-173.

DeMauro MM (1993). Relationship of breeding system to rarity in the lakeside daisy (Hymenoxys acaulis var. glabra). Conserv Biol 7: 542-550.

Doyle JJ, Doyle JL (1987). A rapid DNA isolation procedure for small quantities of fresh leaf tissue. Phytochem Bull 19: 11-15.

Drummond AJ, Ashton B, Buxton S, Cheung M, Cooper A, Duran C et al. (2011). Geneious $\checkmark$ 7.1.4. Created by Biomatters. Available from http://www.geneious.com/.

Earl DA (2012). STRUCTURE HARVESTER: a website and program for visualizing STRUCTURE output and implementing the Evanno method. Conserv Genet Resour 4: 359-361.

Ellstrand NC, Elam DR (1993). Population genetic consequences of small population size: implications for plant conservation. Annu Rev Ecol Syst 24: 217-242.

Evanno G, Regnaut S, Goudet J (2005). Detecting the number of clusters of individuals using the software STRUCTURE: a simulation study. Mol Ecol 14: 2611-2620.

Falush D, Stephens M, Pritchard JK (2003). Inference of population structure using multilocus genotype data: linked loci and correlated allele frequencies. Genetics 164: 1567-1587. 
Ford HA, Paton DC (1982). Partitioning of nectar sources in an Australian honeyeater community. Aust J Ecol 7: 149-159.

Ford HA, Paton DC, Forde N (1979). Birds as pollinators of Australian plants. N Z J Bota 17: 509-519.

Harder CM, Potts BM (1997). Postdispersal selection following mixed mating in Eucalyptus regnans. Evolution 51: 103-111.

Harder LD, Barrett SCH (1996). Pollen dispersal and mating patterns in animal-pollinated plants. In: Lloyd DG (ed). Floral Biology. Springer: USA. pp 140-190.

Hardner C, Potts B (1995). Inbreeding depression and changes in variation after selfing in Eucalyptus globulus ssp. globulus. Silvae Genet 44: 46-54.

Hopper SD (1981). Honeyeaters and their winter food plants on granite rocks in the central wheatbelt of Western Australia. Wildlife Res 8: 187-197.

Hopper SD (2009). OCBIL theory: towards an integrated understanding of the evolution, ecology and conservation of biodiversity on old, climatically buffered, infertile landscapes. Plant Soil 322: 49-86.

Hopper SD, Campbell NA, Moran GF (1982). Eucalyptus caesia, a rare mallee of granite rocks from south-western Australia. In: Groves RH (ed). Species at Risk. Research in Australia. Australian Academy of Science: Canberra. pp 46-61.

Hopper SD, Gioia P (2004). The southwest Australian floristic region: evolution and conservation of a global hot spot of biodiversity. Annu Rev Ecol Evol Syst 35: 623-650.

Hopper SD, Moran GF (1981). Bird pollination and the mating system of Eucalyptus stoatei. Aust J Bot 29: 625-638.

Hopper SD, Silveira FA, Fiedler PL (2016). Biodiversity hotspots and Ocbil theory. Plant Soil 403: 167-216

Hopper SD, Van Leeuwen S, Brown A, Patrick S (1990). Western Australia's Endangered Flora. Dept of Conservation and Land Management: Perth, Western Australia.

House SM (1997). Reproductive biology of eucalypts. In: Williams J (ed.). Eucalyp Ecology: Individuals to Ecosystems. Cambridge University Press: Cambridge. pp 30-55.

Husband BC, Schemske DW (1996). Evolution of the magnitude and timing of inbreeding depression in plants. Evolution 50: 54-70.

Iddrisu MN, Ritland K (2004). Genetic variation, population structure, and mating system in bigleaf maple (Acer macrophyllum Pursh.). Can J Bot 82: 1817-1825.

Ismail S, Ghazoul J, Ravikanth G, Uma Shaanker R, Kushalappa C, Kettle C (2012). Does long-distance pollen dispersal preclude inbreeding in tropical trees? Fragmentation genetics of Dysoxylum malabaricum in an agro-forest landscape. $\mathrm{Mol}$ Ecol 21: 5484-5496.

James S, Kennington W (1993). Selection against homozygotes and resource allocation in the mating system of Eucalyptus camaldulensis Dehnh. Aust J Bot 41: 381-391.

Jennions MD, Petrie M (2000). Why do females mate multiply? A review of the genetic benefits. Biol Rev Camb Philos Soc 75: 21-64.

Jones F, Hamrick J, Peterson C, Squiers E (2006). Inferring colonization history from analyses of spatial genetic structure within populations of Pinus strobus and Quercus rubra. Mol Ecol 15: 851-861.

Kalinowski ST (2011). The computer program STRUCTURE does not reliably identify the main genetic clusters within species: simulations and implications for human population structure. Heredity 106: 625-632.

Kalinowski ST, Taper ML, Marshall TC (2007). Revising how the computer program CERVUS accommodates genotyping error increases success in paternity assignment. Mol Ecol 16: 1099-1106.

Karron JD, Marshall DL (1990). Fitness consequences of multiple paternity in wild radish, Raphanus sativus. Evolution 44: 260-268.

Karron JD, Mitchell RJ, Bell JM (2006). Multiple pollinator visits to Mimulus ringens (Phrymaceae) flowers increase mate number and seed set within fruits. Am J Bot 93: $1306-1312$

Keighery GJ (1980). Bird pollination in south Western Australia: a checklist. Plant Syst Evol 135: 171-176.

Knight TM, Steets JA, Vamosi JC, Mazer SJ, Burd M, Campbell DR et al. (2005). Pollen limitation of plant reproduction: pattern and process. Annu Rev Ecol Evol Syst 36: 467-497.

Kramer AT, Ison JL, Ashley MV, Howe HF (2008). The paradox of forest fragmentation genetics. Conserv Biol 22: 878-885.

Krauss SL, He T, Barrett LG, Lamont BB, Enright NJ, Miller BP et al. (2009). Contrasting impacts of pollen and seed dispersal on spatial genetic structure in the bird-pollinated Banksia hookeriana. Heredity 102: 274-285.

Levin DA, Kerster HW (1974). Gene flow in seed plants. In: Dobzhansky T (ed). Evolutionary Biology. Vol. 7. Springer: US, pp 139-220.

Llaurens V, Castric V, Austerlitz F, Vekemans X (2008). High paternal diversity in the selfincompatible herb Arabidopsis halleri despite clonal reproduction and spatially restricted pollen dispersal. Mol Ecol 17: 1577-1588.

Llorens TM, Byrne M, Yates CJ, Nistelberger HM, Coates DJ (2012). Evaluating the influence of different aspects of habitat fragmentation on mating patterns and pollen dispersal in the bird-pollinated Banksia sphaerocarpa var. caesia. Mol Ecol 21: 314-328.
Mac Nally R, Timewell CAR, Burger AE (2005). Resource availability controls birdassemblage composition through interspecific aggression. Auk 122: 1097-1111.

Millar MA, Byrne M, Coates DJ, Stuckely MJC, McComb JA (2000). Mating system studies in jarrah, Eucalyptus marginata (Myrtaceae). Aust J Bot 48: 475-479.

Mimura M, Barbour RC, Potts BM, Vaillancourt RE, Watanabe KN (2009). Comparison of contemporary mating patterns in continuous and fragmented Eucalyptus globulus native forests. Mol Ecol 18: 4180-4192.

Mitchell RJ, Wilson WG, Holmquist KG, Karron JD (2013). Influence of pollen transport dynamics on sire profiles and multiple paternity in flowering plants. PLoS One 8: e76312.

Moran GF, Hopper SD (1983). Genetic diversity and the insular population structure of the rare granite rock species, Eucalyptus caesia Benth. Aust J Bot 31: 161-172.

Morris WF, Mangel M, Adler FR (1995). Mechanisms of pollen deposition by insect pollinators. Evol Ecol 9: 304-317.

Muona O, Moran GF, Bell JC (1991). Hierarchical patterns of correlated mating in Acacia melanoxylon. Genetics 127: 619-626.

Nistelberger HM, Coates DJ, Llorens TM, Yates CJ, Byrne M (2015). A cryptic genetic boundary in remnant populations of a long-lived, bird-pollinated shrub Banksia sphaerocarpa var. caesia (Proteaceae). Biol J Linn Soc 115: 241-255.

Pannell JR, Labouche AM (2013). The incidence and selection of multiple mating in plants. Philos Trans R Soc B Biol Sci 368: 20120051.

Pardini E, Hamrick J (2008). Inferring recruitment history from spatial genetic structure within populations of the colonizing tree Albizia julibrissin (Fabaceae). Mol Ecol 17: 2865-2879.

Paton DC (1993). Honeybees in the Australian environment. Bioscience 43: 95-103.

Peakall R, Smouse PE (2006). GENALEX 6: genetic analysis in Excel. Population genetic software for teaching and research. Mol Ecol Notes 6: 288-295.

Peakall R, Smouse PE (2012). GenAIEx 6.5: genetic analysis in Excel. Population genetic software for teaching and research-an update. Bioinformatics 28: 2537-2539.

Phillips RD, Hopper SD, Dixon KW (2010). Pollination ecology and the possible impacts of environmental change in the Southwest Australian Biodiversity Hotspot. Philos Trans $R$ Soc B Biol Sci 365: 517-528.

Phillips RD, Steinmeyer F, Menz MHM, Erickson TE, Dixon KW (2014). Changes in the composition and behaviour of a pollinator guild with plant population size and the consequences for plant fecundity. Funct Ecol 28: 846-856.

Pritchard JK, Stephens M, Donnelly P (2000). Inference of population structure using multilocus genotype data. Genetics 155: 945-959.

Pyke GH (1984). Optimal foraging theory: a critical review. Annu Rev Ecol Syst 15: 523-575.

R Core Team (2014). R: A Language and Environment for Statistical Computing R Foundation for Statistical Computing: Vienna, Austria. Available from http://www.Rproject.org/.

Ramsey M (1988). Differences in pollinator effectiveness of birds and insects visiting Banksia menziesii (Proteaceae). Oecologia 76: 119-124.

Ritchie AL, Krauss SL (2012). A genetic assessment of ecological restoration success in Banksia attenuata. Restoration Ecol 20: 441-449.

Ritland K (2002). Extensions of models for the estimation of mating systems using $n$ independent loci. Heredity 88: 221-228.

Roberts DG, Ottewell KM, Whelan RJ, Ayre DJ (2014). Is the post-disturbance composition of a plant population determined by selection for outcrossed seedlings or by the composition of the seedbank? Heredity 112: 409-414.

Sampson JF (1998). Multiple paternity in Eucalyptus rameliana (Myrtaceae). Heredity 81: 349-355.

Slate J, Marshall T, Pemberton J (2000). A retrospective assessment of the accuracy of the paternity inference program CERVUS. Mol Ecol 9: 801-808.

Smith S, Hughes J, Wardell-Johnson G (2003). High population differentiation and extensive clonality in a rare mallee eucalypt: Eucalyptus curtisii. Conservation genetics of a rare mallee eucalypt. Conserv Genet 4: 289-300.

Southerton SG, Birt P, Porter J, Ford HA (2004). Review of gene movement by bats and birds and its potential significance for eucalypt plantation forestry. Aust Forestry 67: 44-53.

Steane D, Vaillancourt R, Russell J, Powell W, Marshall D, Potts B (2001). Development and characterisation of microsatellite loci in Eucalyptus globulus (Myrtaceae). Silvae Genet 50: 89-91.

Visscher PK, Seeley TD (1982). Foraging strategy of honeybee colonies in a temperate deciduous forest. Ecology 63: 1790-1801.

Wellington AB, Noble IR (1985). Seed dynamics and factors limiting recruitment of the mallee Eucalyptus incrassata in semi-arid, south-eastern Australia J Ecol 73. 657-666.

Yates CJ, Coates DJ, Elliott C, Byrne M (2007). Composition of the pollinator community, pollination and the mating system for a shrub in fragments of species rich kwongan in south-west Western Australia. Biodivers Conserv 16: 1379-1395.

Yates CJ, Ladd PG (2004). Breeding system, pollination and demography in the rare granite endemic shrub Verticordia staminosa ssp. staminosa in south-west Western Australia. Austral Ecol 29: 189-200.

Supplementary Information accompanies this paper on Heredity website (http://www.nature.com/hdy) 